\title{
Características morfofisiológicas e produtividade da palma forrageira em diferentes lâminas de irrigação
}

\author{
Maria G. de Queiroz ${ }^{1}$, Thieres G. F. da Silva ${ }^{2}$, Sérgio Zolnier ${ }^{3}$, \\ Servulo M. S. e Silva ${ }^{4}$, Lucivânia R. Lima ${ }^{2}$ \& Jandelson de O. Alves ${ }^{2}$ \\ ${ }^{1}$ Programa de Pós-Graduação em Meteorologia Agrícola/Departamento de Engenharia Agrícola/Universidade Federal de Viçosa. Viçosa, MG. E-mail: \\ mg.gabi@hotmail.com (Autora correspondente) \\ ${ }^{2}$ Unidade Acadêmica de Serra Talhada/Universidade Federal Rural de Pernambuco. Serra Talhada, PE. E-mail: thieres@uast.ufrpe.br; \\ lucivania_rodrigues@hotmail.com; jandelson13@gmail.com \\ ${ }^{3}$ Departamento de Engenharia Agrícola/Universidade Federal de Viçosa. Viçosa, MG. E-mail: zolnier@ufv.br \\ ${ }^{4}$ Instituto Agronômico de Pernambuco. Arcoverde, PE. E-mail: servulo.siqueira@ipa.br
}

Palavras-chave:

análise de crescimento

Opuntia stricta

Semiárido

\begin{abstract}
R E S U M O
Muitas são as suposições quanto à baixa exigência de água da palma mas tais informações dependem de estudos de análise do desempenho da cultura a diferentes condições hídricas. Assim, objetivou-se verificar o efeito de diferentes lâminas de irrigação sobre a morfofisiologia e desempenho produtivo da palma forrageira cultivada em ambiente Semiárido. O experimento foi conduzido no segundo ano produtivo da cultura, em Serra Talhada, PE. As lâminas de água aplicadas totalizaram, ao final do ciclo, 976, 1048, 1096, 1152 e $1421 \mathrm{~mm}$. Na ocasião da colheita foram feitas medidas biométricas e de biomassa das plantas e em seguida obtidos índices de resposta hídrica, morfológicos, morfofisiológicos e feita análise de produtividade. Verificou-se que as lâminas de irrigação não afetaram os índices de resposta hídrica (com exceção do peso fresco do cladódio de $1^{\text {a }}$ ordem), morfológicos e morfofisiológicos ( $\left.p>0,05\right)$, assim como o desempenho produtivo; todavia, os valores médios obtidos para a biomassa verde e seca (131,16 e 8,18 $\left.\mathrm{t} \mathrm{ha}^{-1}\right)$ e do número de cladódios totais (14,13 unid.), se mostraram superiores aos relatos de cultivos em condições de sequeiro. Sugerem-se condições de disponibilidade hídrica de 1048 a $1096 \mathrm{~mm} \mathrm{ano}^{-1}$ para a palma forrageira.
\end{abstract}

Key words:

growth analysis

Opuntia stricta

Semiarid

\section{Morphophysiological characteristic and yield of forage cactus under different irrigation depths}

\begin{abstract}
A B S T R A C T
There are many assumptions about the low water requirement of forage cactus, but such information depends on performance analysis studies of the crop under different water conditions. Thus, this study aimed to verify the effect of different irrigation depths on morphophysiology and productive performance of forage cactus grown in semiarid environment. The experiment was conducted during the second productive year of the crop in Serra Talhada, PE. Water depths were applied and recorded at the end of the cycle as 976, $1048,1096,1152$ and $1421 \mathrm{~mm}$. At harvest, biometric and plant biomass measurements were made, and water response indices, morphological, morphophysiological and yield analysis were obtained. It was found that the irrigation depth did not affect the water response indices (except for $1^{\text {st }}$ cladode fresh weight), morphological and morphophysiological $(p>0.05)$, as well as the productive performance. However, the mean values obtained for the yield, such as green and dry biomass (131.16 and $8.18 \mathrm{tha}^{-1}$ ), and growth variables, such as average total cladodes number (14.13), showed to be superior to reported under rainfed conditions. Water availability conditions of 1048 to $1096 \mathrm{~mm} \mathrm{yr}^{-1}$ for the forage cactus are suggested.
\end{abstract}




\section{INTRODUÇÃo}

Nas regiões Semiáridas as atividades agrícolas devem ser manejadas de maneira que o sistema de produção seja o mais sustentável possível. Para isto, é essencial o uso de espécies adaptadas às condições climáticas reinantes com destaque para altas temperaturas e déficit hídrico (Oliveira et al., 2010; Pinheiro et al., 2014). A palma forrageira (Opuntia sp. e Nopalea sp.); por ser uma cactácea, possui boa adaptação às regiões áridas e semiáridas, apresentando tolerância a períodos longos de estiagem e alta eficiência no uso de água (Flores-Hernández et al., 2004; Dubeux Júnior et al., 2006; Bispo et al., 2007; Pinheiro et al., 2014; Silva et al., 2015).

Inúmeras são as suposições quanto à baixa exigência hídrica da palma (Consoli et al., 2013; Silva et al., 2014a) o que se deve ao fato da mesma possuir metabolismo ácido das crassuláceas (MAC) e ser cultivada tradicionalmente em condições de sequeiro. Resultados de pesquisas ainda têm constatado que a produtividade de matéria seca é inferior à de outras plantas de potencial forrageiro, também utilizadas no Semiárido (Oliveira et al., 2010).

Tais considerações induzem à necessidade de estudos de análise do desempenho da palma submetida a diferentes condições de disponibilidade de água, que possibilitem a melhoria da compreensão da resposta da cultura e a definição de sua exigência hídrica que podem ser úteis para a maximização da sua produtividade (Costa et al., 2012).

Neste contexto, medidas de dimensões lineares e biomassa das plantas obtidas em intervalos de tempo regulares podem ser usadas no cálculo de índices morfofisiológicos (Silva et al., 2009), bem como índices de resposta hídrica e morfológicos, conforme sugerido no presente estudo. Para a palma forrageira estudos desta natureza ainda são incipientes de modo que sua determinação contribui para o aperfeiçoamento do uso da água no âmbito agrícola. Assim, objetivou-se verificar o efeito da aplicação de diferentes lâminas de irrigação na morfofisiologia e no desempenho produtivo da palma forrageira cultivada em ambiente Semiárido.

\section{Material e Métodos}

O experimento foi conduzido na Estação Experimental Lauro Ramos Bezerra, pertencente ao Instituto Agronômico de Pernambuco (IPA), localizada no município de Serra Talhada (Lat. 7o 59’ S, Long. 38 15’ O e Alt. $461 \mathrm{~m}$ ) em ambiente Semiárido, estado de Pernambuco.

Analisou-se o clone Orelha de Elefante Mexicana, IPA200016 (OEM), da espécie Opuntia stricta, disposta no espaçamento de $1,6 \times 0,4 \mathrm{~m}$.

A área foi implantada em março de 2011 sendo realizado apenas um corte, que ocorreu em maio de 2012 até o início do ciclo experimental, que foi conduzido até junho de 2013 quando, por ocasião de uma nova colheita, foram preservados apenas os cladódios basais nas plantas, totalizando 380 dias de ciclo.

O delineamento experimental empregado foi em blocos ao acaso, com cinco tratamentos (lâminas de irrigação: 0; 8,$75 ; 17,5 ; 26,35$ e $35 \%$ da evapotranspiração de referência) e quatro repetições, sendo as parcelas constituídas por quatro fileiras com quinze plantas cada uma totalizando 60 plantas sendo a área total da parcela de $28,8 \mathrm{~m}^{2}$.

Para a aplicação das lâminas foi adotado o sistema de irrigação por gotejamento, com emissores espaçados a 0,40 $\mathrm{m}$, posicionados a uma distância de $0,25 \mathrm{~m}$ das plantas, operando com uma pressão de $1,32 \pm 0,12 \mathrm{~L} \mathrm{~h}^{-1}$.

No período compreendido entre 18 e 186 dias após o corte (DAC) foram aplicadas lâminas de irrigação equivalentes a $607 \mathrm{~mm}$, para suprir a deficiência hídrica gerada pelos baixos níveis pluviométricos ocorridos na região $(29 \mathrm{~mm})$. Após os 186 DAC o manejo do sistema de irrigação foi realizado com diferenciação das lâminas de água. Neste período os eventos de precipitação pluviométrica foram de $364 \mathrm{~mm}$, o que totalizou $393 \mathrm{~mm}$ durante todo o período experimental.

A estimativa da evapotranspiração de referência foi obtida por meio da equação de Penman-Monteith, parametrizada conforme o Boletim 56 da FAO (Allen et al., 1998), usandose dados de uma estação meteorológica localizada a aproximadamente $700 \mathrm{~m}$ da área experimental, pertencente ao Instituto Nacional de Meteorologia (INMET).

Ao longo do período experimental a evapotranspiração real da cultura (ET) foi quantificada por meio do método do balanço de água no solo (BAS), conforme Eq.1:

$$
-\mathrm{ET}=\mathrm{P}+\mathrm{I} \pm \mathrm{Q} \pm \Delta \mathrm{A}
$$

em que:

$\mathrm{P}$ - precipitação pluviométrica, $\mathrm{mm}$;

I - irrigação de acordo com cada tratamento, $\mathrm{mm}$;

Q - fluxo vertical de água no solo, mm; e

$\Delta \mathrm{A}$ - variação do armazenamento de água no solo, $\mathrm{mm}$.

Neste caso, consideraram-se os fluxos horizontais e o escoamento superficial como inexistentes e/ou nulos, uma vez que o plantio da cultura foi feito em curvas de nível e as lâminas de irrigação aplicadas por sistema localizado (gotejamento); além disto, os eventos de precipitação pluviométrica foram baixos (393 $\mathrm{mm})$.

$Q$ foi determinado utilizando-se a equação de DarcyBuckingham, por meio de dados de conteúdo de água no solo e equações físico-hídricas do solo calibradas localmente, conforme descrito por Araújo Primo et al. (2015). A $\Delta \mathrm{A}$ foi determinada a partir da medição do conteúdo de água no solo, a qual foi feita por meio de uma sonda capacitiva (Diviner $2000^{\circ}$, Sentek Pty Ltda., Austrália), calibrada localmente (Araújo Primo et al., 2015), em que foram instalados em cada parcela, tubos de acesso de $1 \mathrm{~m}$ de profundidade. As leituras foram realizadas três vezes por semana (segundas, quartas e sextas-feiras), sempre antes dos eventos de irrigação. Após a determinação dos componentes do BAS, a ET foi obtida por resíduo.

$\mathrm{Na}$ ocasião da colheita foram desprezadas as fileiras das extremidades de cada parcela, as duas primeiras e as duas últimas plantas das fileiras centrais proporcionando, assim, uma parcela útil constituída de 22 plantas. Todas as plantas da parcela útil foram pesadas e contabilizadas quanto ao número total de cladódios por planta. 
Uma planta representativa por parcela experimental, quatro por tratamento, foi usada para a realização de análises biométricas e de biomassa. Nesta, ainda em campo, foi medida a altura (AP) (maior distância vertical entre a superfície do solo e a extremidade superior do cladódio mais alto) e largura da planta (LP) (maior largura horizontal entre cladódios das extremidades), e identificados os cladódios quanto à ordem de surgimento na planta. Em laboratório foram feitos a contagem do número de cladódios por ordem, a medição do comprimento (CC), largura (LC) e o perímetro (PC) dos cladódios com fita métrica e, por meio de um paquímetro, a determinação da espessura (EC), sendo todas as medições efetuadas no terço médio do cladódio; em seguida, os cladódios foram pesados individualmente em uma balança (Modelo ARD110, Ohaus Corporation, USA) com $\pm 0,01 \mathrm{~g}$ de precisão, para obtenção do peso fresco (PFC).

Finalmente, os cladódios foram fragmentados, acondicionados em sacos de papel e mantidos em uma estufa de circulação forçada a $65^{\circ} \mathrm{C}$ até se obter peso seco constante.

A matéria seca total da planta foi determinada pela soma do peso individual de todos os cladódios; posteriormente foi calculada a porcentagem do conteúdo de matéria seca das plantas pela relação entre a matéria seca e verde; os dados de rendimento foram extrapolados para toneladas por hectare, usando-se a matéria seca da planta, o peso verde da parcela experimental e o número de plantas por hectare.

Foram utilizados modelos matemáticos pré-ajustados para determinação da área dos cladódios (AC) do clone Orelha de Elefante Mexicana (Silva et al., 2014b); o índice de área do cladódio (IAC), em $\mathrm{m}^{2} \mathrm{~m}^{-2}$, foi obtido por meio do produto entre os valores médios de AC por ordem e o número total de cladódios da planta por ordem, divididos pelo espaçamento adotado (1,6 x 0,4 m).

Com os dados biométricos de biomassa e de ET, foram propostos, no presente estudo, índices de resposta hídrica e morfológicos para a palma forrageira além de calculados os índices morfofisiológicos da cultura.

Os índices de resposta hídrica (IRH) mostram a evolução das variáveis do crescimento em função do consumo de água pela cultura; para isto, assumiu-se a relação entre os dados biométricos, na ocasião da colheita, e os valores acumulados de ET para o ciclo:

$$
\mathrm{IRH}=\frac{\mathrm{Xn}}{\mathrm{ET}}
$$

em que:

$\mathrm{Xn}$ - dado biométrico da variável $\mathrm{n}$, em $\mathrm{mm} \mathrm{m}^{-1}$ ou unid. $\mathrm{mm}^{-1}$ ou $\mathrm{g} \mathrm{mm}^{-1}$ ou $\mathrm{mm}^{2} \mathrm{~mm}^{-1}$.

Para os índices morfológicos propostos foram usados os dados biométricos dos cladódios e das plantas, e os de biomassa, sendo calculados: índice de cobertura do solo (ICS), índice de volume de produção (IVP), índice de distribuição de área fotossintética (IDAF) e índice de distribuição de cladódios da planta (IDCP).

O ICS representa a área de ocupação da planta considerando-se a largura da planta e o espaçamento entre linhas, sendo expresso em termos de porcentagem (Eq. 3).

$$
\mathrm{CIS}=100\left[\frac{\left(\frac{\pi \mathrm{L}^{2}}{4}\right)}{\left(\frac{\pi 1,6^{2}}{4}\right)}\right]
$$

em que:

L - largura da planta, m; e

1,6 - representa o espaçamento entre as plantas, $\mathrm{m}$.

O IVP representa o volume de área de planta por produção de biomassa seca considerando-se as dimensões lineares AP e LP, expressas em $\mathrm{m}^{3} \mathrm{~kg}^{-1}$ (Eq. 4).

$$
\mathrm{IVP}=\left[\frac{\operatorname{AP}\left(\frac{\pi \mathrm{L}^{2}}{4}\right)}{\frac{1.000 \mathrm{MS}}{15.625}}\right]
$$

em que:

AP - altura da planta, $\mathrm{m}$;

MS - matéria seca, $\mathrm{t} \mathrm{ha}^{-1}$; e

15625 - população de plantas da área oriunda do espaçamento adotado.

Para verificar a contribuição dos cladódios das diferentes ordens de surgimento no IAC total da planta, foi utilizado o IDAF, expresso em \%, (Eq. 5).

$$
\mathrm{IDAF}=100\left[\frac{\left(\frac{\mathrm{AC}_{\mathrm{n}} \mathrm{NC}_{\mathrm{n}}}{10.000}\right) /(1,6 \times 0,4)}{\mathrm{IAC}}\right]
$$

em que:

$\mathrm{AC}_{\mathrm{n}}$ e $\mathrm{NC}_{\mathrm{n}}$ - área e número de cladódios da ordem n, em $\mathrm{cm}^{2}$ e unidades, respectivamente; $\mathrm{e}$

IAC - índice de área do cladódio, em $\mathrm{m}^{2} \mathrm{~m}^{-2}$.

Por último, o IDCP indica a distribuição das ordens dos cladódios ao longo da estrutura da planta, expresso em \%, (Eq. 6).

$$
\mathrm{IDCP}=100\left(\frac{\mathrm{NC}_{\mathrm{n}}}{1+\mathrm{NCl}+\ldots+\mathrm{NC}_{\infty}}\right)
$$

em que:

NC1 - número de cladódios de primeira ordem; e

$\mathrm{NC}_{\infty}$ - número de cladódios da ordem infinita.

Finalmente, a partir dos valores da matéria seca total e do IAC por planta foram calculados os índices morfofisiológicos, conforme Silva et al. (2009): taxa de assimilação líquida (TAL, $\mathrm{g} \mathrm{m}^{-2}$ mês $^{-1}$ ), taxa de crescimento absoluto (TCA, $\mathrm{g} \mathrm{m}^{-2}$ mês $^{-1}$ ) e taxa de crescimento relativo (TCR, $\mathrm{g} \mathrm{g}^{-1} \mathrm{mês}^{-1}$ ), assim como a área foliar específica (AFE, $\mathrm{cm}^{2} \mathrm{~g}^{-1}$ ) porém uma vez que a palma forrageira possui cladódios ao invés de folhas, a AFE foi denominada área do cladódio específica (ACE, $\left.\mathrm{cm}^{2} \mathrm{~g}^{-1}\right)$. 
Esses índices foram calculados sem incluir a biomassa no início do ciclo da cultura; não se considerou o peso médio do cladódio basal visto que este não foi colhido e assim não foi computado nos valores da biomassa final.

Para comparação entre as diferentes condições de disponibilidade de água, os índices de resposta hídrica, morfológicos e morfofisiológicos e a produtividade, inicialmente os dados foram submetidos ao teste de Lilliefors para verificação da normalidade e se procedeu, posteriormente, à análise de variância e ao teste de média de Tukey, a nível de 0,05 de probabilidade. Todas as análises estatísticas foram realizadas utilizando-se o programa "Genética Quantitativa e Estatística Experimental" - GENES.

\section{Resultados e Discussão}

As lâminas de água recebidas pelo sistema (somadas precipitação e irrigação) para os tratamentos de $0 ; 8,75 ; 17,5$; 26,35 e $35 \%$ da evapotranspiração de referência foram iguais a 976; 1048; 1096; 1152 e $1202 \mathrm{~mm}$, com diferença entre a menor e maior lâmina fornecida, de apenas $226 \mathrm{~mm}$, as quais resultaram em valores de ET de 855; 986; 1036; 1001 e 1027 $\mathrm{mm}$, nesta ordem; como consequência, as lâminas de irrigação impostas não influenciaram a maioria dos índices de resposta hídrica (Tabela 1) ( $p>0,05)$, com exceção do PFC1.

Já os valores médios desses índices para a AP, LP, NC1, NC2 e NC3, revelam que as evoluções hídricas da AP e da LP, mesmo não apresentando diferenças entre as lâminas, evidenciaram tendência de decréscimo de suas taxas com aumento da lâmina de água aplicada indicando que uma disponibilidade hídrica maior reduz a capacidade de utilização de água para o crescimento da planta. Em termos de número de cladódios emitidos, a palma responde mais rapidamente à emissão daqueles de primeira e segunda ordens (Tabela 1) mostrando que, para suas emissões, a eficiência no uso de água é superior aumentando o crescimento e o desenvolvimento da planta. Este resultado está associado ao hábito de crescimento de espécies de palma forrageira em que os cladódios de ordens inferiores servem de sustentação para a emissão de novos cladódios pela planta (Pinheiro et al., 2014).

$\mathrm{O}$ incremento da disponibilidade hídrica não contribuiu para o aumento significativo da maioria das variáveis de crescimento; entretanto, houve tendência de diminuição da magnitude dos seus valores sob lâminas de irrigação superiores à faixa de $1048 \mathrm{e} 1096 \mathrm{~mm}$.

A ausência de efeito do aumento de lâminas de irrigação sobre o crescimento da cultura pode estar associada à pequena diferença de lâminas entre os tratamentos $(226 \mathrm{~mm})$ ao passo que o excesso de água inibe o desenvolvimento das plantas (Bajgain et al., 2015), sobretudo em espécies cactáceas em que o baixo consumo de água (Silva et al., 2014a) induz a maior manutenção de umidade no solo.

Flores-Hernández et al. (2004) também relatam que o incremento de lâminas de irrigação não promoveu aumento do crescimento de clones de palma forrageira.

Os índices morfológicos não foram afetados pelas diferentes lâminas de irrigação aplicadas (Tabela 2).

Tabela 1. Índices de resposta hídrica de variáveis biométricas em função da evapotranspiração real (valores entre parênteses) da palma forrageira, cv. Orelha de Elefante Mexicana, submetida a diferentes lâminas de irrigação (976; $1048 ; 1096 ; 1152$ e $1202 \mathrm{~mm}$ )

\begin{tabular}{|c|c|c|c|c|c|c|c|}
\hline \multirow{2}{*}{ Variáveis } & \multirow{2}{*}{ Unidades } & $976(855)$ & $1048(986)$ & $1096(1036)$ & $1152(1001)$ & $1202(1027)$ & \multirow{2}{*}{ Média } \\
\hline & & \multicolumn{5}{|c|}{$(\mathrm{mm})$} & \\
\hline AP & $\mathrm{mm} \mathrm{mm}^{-1}$ & 8,82 & 7,36 & 7,67 & 7,51 & 6,61 & 7,59 \\
\hline $\mathrm{LP}$ & $\mathrm{mm} \mathrm{mm}^{-1}$ & 12,30 & 9,78 & 8,21 & 7,98 & 7,74 & 9,20 \\
\hline NC1 & unid. $\mathrm{mm}^{-1}$ & 0,72 & 1,09 & 0,68 & 0,68 & 0,76 & 0,79 \\
\hline NC2 & unid. $\mathrm{mm}^{-1}$ & 0,92 & 1,00 & 0,74 & 0,53 & 0,63 & 0,76 \\
\hline NC3 & unid. $\mathrm{mm}^{-1}$ & 0,31 & 0,03 & 0,03 & 0,09 & 0,05 & 0,01 \\
\hline PFC1 & $\mathrm{g} \mathrm{mm}^{-1}$ & $0,78 a b$ & $0,59 \mathrm{~b}$ & $0,83 \mathrm{a}$ & $0,58 \mathrm{~b}$ & $0,60 a b$ & - \\
\hline $\mathrm{CC} 1$ & $\mathrm{~mm} \mathrm{~mm}^{-1}$ & 2,78 & 2,54 & 2,72 & 2,30 & 2,52 & 2,57 \\
\hline LC1 & $\mathrm{mm} \mathrm{mm-1}$ & 2,46 & 2,09 & 2,28 & 2,08 & 2,10 & 2,20 \\
\hline EC1 & $\mathrm{mm} \mathrm{mm}^{-1}$ & 0,02 & 0,015 & 0,015 & 0,015 & 0,018 & 0,017 \\
\hline PC1 & $\mathrm{mm} \mathrm{mm}^{-1}$ & 8,12 & 6,80 & 7,72 & 6,80 & 6,87 & 7,26 \\
\hline PSC1 & $\mathrm{g} \mathrm{mm}^{-1}$ & 0,05 & 0,04 & 0,05 & 0,038 & 0,04 & 0,044 \\
\hline $\mathrm{AC} 1$ & $\mathrm{~mm}^{2} \mathrm{~mm}^{-1}$ & 40,33 & 36,52 & 44,84 & 33,23 & 37,77 & 38,54 \\
\hline PFC2 & $\mathrm{g} \mathrm{mm}^{-1}$ & 0,61 & 0,54 & 0,52 & 0,57 & 0,36 & 0,52 \\
\hline CC2 & $\mathrm{mm} \mathrm{mm}^{-1}$ & 3,26 & 2,92 & 2,86 & 2,7 & 2,02 & 2,75 \\
\hline LC2 & $\mathrm{mm} \mathrm{mm}^{-1}$ & 2,5 & 2,31 & 2,08 & 2,06 & 1,49 & 2,09 \\
\hline EC2 & $\mathrm{mm} \mathrm{mm}^{-1}$ & 0,013 & 0,01 & 0,01 & 0,013 & 0,008 & 0,01 \\
\hline PC2 & $\mathrm{mm} \mathrm{mm}^{-1}$ & 8,89 & 8,01 & 7,57 & 6,97 & 5,34 & 7,36 \\
\hline PSC2 & $\mathrm{g} \mathrm{mm}^{-1}$ & 0,04 & 0,038 & 0,033 & 0,035 & 0,023 & 0,034 \\
\hline $\mathrm{AC2}$ & $\mathrm{mm}^{2} \mathrm{~mm}^{-1}$ & 49,44 & 46,73 & 43,34 & 40,67 & 29,79 & 41,81 \\
\hline PFC3 & $\mathrm{g} \mathrm{mm}^{-1}$ & 0,19 & 0,27 & 0,12 & 0,14 & 0,08 & 0,16 \\
\hline CC3 & $\mathrm{mm} \mathrm{mm^{-1 }}$ & 1,46 & 0,90 & 0,97 & 0,89 & 0,5 & 0,94 \\
\hline LC3 & $\mathrm{mm} \mathrm{mm}^{-1}$ & 1,17 & 0,73 & 0,68 & 0,62 & 0,47 & 0,73 \\
\hline EC3 & $\mathrm{mm} \mathrm{mm}^{-1}$ & 0,005 & 0,005 & 0,003 & 0,003 & 0,003 & 0,003 \\
\hline PC3 & $\mathrm{mm} \mathrm{mm}^{-1}$ & 3,93 & 2,47 & 2,52 & 2,31 & 1,48 & 2,54 \\
\hline PSC3 & $\mathrm{g} \mathrm{mm}^{-1}$ & 0,015 & 0,018 & 0,008 & 0,008 & 0,005 & 0,01 \\
\hline AC3 & $\mathrm{mm}^{2} \mathrm{~mm}^{-1}$ & 18,88 & 17,43 & 11,79 & 13,42 & 7,50 & 13,80 \\
\hline
\end{tabular}

NTC - Número total de cladódios médios por planta; AP - Altura da planta; LP - Largura da planta; NC - Número de cladódios por ordem; CC - Comprimento dos cladódios; LC - Largura dos cladódios; EC - Espessura dos cladódios; PC - Perímetro dos cladódios; AC - Área dos cladódios; PFC - Peso fresco dos cladódios; PSC - Peso seco dos cladódios; 1,2 e 3 - Ordens dos cladódios; Médias seguidas pelas mesmas letras minúsculas na horizontal não diferem entre si estatisticamente $(P>0,05)$ pelo Teste de Tukey 
Tabela 2. Índices morfológicos da palma forrageira, cv. Orelha de Elefante Mexicana, submetida a diferentes lâminas de irrigação $(976 ; 1048 ; 1096 ; 1152$ e 1202 mm)

\begin{tabular}{|c|c|c|c|c|c|c|c|}
\hline \multirow{2}{*}{ Variáveis } & \multirow{2}{*}{ Unidades } & 976 & 1048 & 1096 & 1152 & 1202 & \multirow{2}{*}{ Média } \\
\hline & & & & $(\mathrm{mm})$ & & & \\
\hline ICS & $\%$ & 43,70 & 36,91 & 28,32 & 25,96 & 25,76 & 32,13 \\
\hline IVP & $\mathrm{m}^{3} \mathrm{~kg}^{-1}$ & 1,25 & 1,06 & 0,87 & 0,76 & 0,78 & 0,94 \\
\hline IDAF-00 & $\%$ & 2,92 & 2,24 & 4,71 & 4,43 & 4,04 & 3,67 \\
\hline IDAF-01 & $\%$ & 37,51 & 46,86 & 49,01 & 54,23 & 54,9 & 48,50 \\
\hline IDAF-02 & $\%$ & 49,21 & 49,53 & 45,05 & 37,35 & 38,78 & 43,98 \\
\hline IDAF-03 & $\%$ & 10,36 & 1,38 & 1,24 & 4,01 & 2,28 & 3,85 \\
\hline IDCP-00 & $\%$ & 5,89 & 4,9 & 6,64 & 8,83 & 7,64 & 6,78 \\
\hline IDCP-01 & $\%$ & 36,82 & 50,52 & 47,61 & 55,25 & 53,13 & 48,67 \\
\hline IDCP-02 & $\%$ & 44,69 & 43,65 & 44,10 & 32,35 & 36,46 & 40,25 \\
\hline IDCP-03 & $\%$ & 12,61 & 0,93 & 1,66 & 3,57 & 2,78 & 4,31 \\
\hline
\end{tabular}

ICS - Índice de cobertura do solo; IVP - Índice de volume de produção IDAF-0 - Índice de distribuição de área fotossintética por ordem; IDCP-0 - Índice de distribuição de cladódios da planta por ordem; 1 , 2 e 3 - Ordens dos cladódios; Médias seguidas pelas mesmas letras minúsculas na horizontal não diferem entre si estatisticamente (P > 0,05) pelo Teste de Tukey

O ICS de $32 \%$ indica que o manejo usado não promoveu a máxima ocupação da cultura na superfície do solo, o qual pode estar relacionado ao espaçamento adotado para o sistema irrigado; por sua vez, o valor médio do IVP sugere que $1 \mathrm{~kg}$ de biomassa seca ocupa um volume de $0,94 \mathrm{~m}^{3}$ na planta. O IDCP, que representa a distribuição das ordens dos cladódios na planta mostrou que, aos $380 \mathrm{DAC}$, há maior ocorrência de cladódios primários, seguidos dos secundários, basais e terciários (Tabela 2).

É importante ressaltar que, à medida que a planta cresce ela estabiliza a emissão daqueles de primeira ordem e prioriza a emissão dos cladódios de ordens superiores (Ramos et al., 2011), sendo que, neste trabalho as plantas ainda estavam iniciando a emissão dos cladódios de terceira ordem.

O índice de distribuição de área fotossintética (IDAF) fornece informações a respeito da contribuição das diferentes ordens dos cladódios no IAC total da planta, responsável pela fotossíntese. Observa-se que os cladódios de primeira ordem são aqueles com maior disponibilidade de superfície assimiladora e, como tal, são os principais responsáveis pela sustentação da planta e distribuição de nutrientes e água para os demais órgãos.

Em seguida, a maior partição do IAC ocorre nos cladódios de segunda ordem, terceira ordem e basais (Tabela 2). Devido os cladódios de terceira ordem se encontrarem novos e pequenos, com valores de área foliar baixos $\left( \pm 129,2 \mathrm{~cm}^{2}\right)$ sua contribuição ao IAC ainda é pouco expressiva. Verifica-se que, sempre que a planta emite novas ordens de cladódios, os valores de IDAF são menores nos cladódios de ordens inferiores.

Verificou-se que, em termos produtivos, não houve diferenças no número de cladódios, biomassa verde e seca anual entre os distintos tratamentos (Figura 1A, 1B e 1C), revelando que o acréscimo de irrigação não contribuiu para aumentar o rendimento da cultura. Oliveira et al. (2010) informaram que regiões com regime pluviométrico acima de $1000 \mathrm{~mm} \mathrm{ano}^{-1}$ podem resultar em baixa produtividade da cultura devido provavelmente ao excesso hídrico local.

Todavia, Flores-Hernández et al. (2004) verificaram que a irrigação suplementar não proporcionou incrementos na produção de cladódios verdes e produtividade de matéria seca nem nos valores de IAC; esses autores realizaram o manejo de irrigação com base em percentuais de evaporação do Tanque Classe A, acumulada semanalmente, resultando em lâminas de 740, 1060 e $1380 \mathrm{~mm}$ anuais, em quatro clones de palma forrageira de diferentes espécies do gênero Opuntia.

Oliveira Júnior et al. (2009) e Ramos et al. (2011) encontraram, analisando o clone italiana do gênero Opuntia no Semiárido paraibano, o valor médio de 11,0 cladódios aos 330 dias após plantio (DAP) e 11,5 cladódios, aos 445 DAP, respectivamente.

Leite (2009) mostra que existe ampla variação do conteúdo de matéria seca da palma forrageira, em função do cultivar e do manejo adotado. A média dos parâmetros produtivos encontrados no presente estudo (Figura 1) está acima daquelas verificadas por outros autores (Flores-Hernández et al., 2004; Silva et al., 2010; Nascimento et al., 2011).

Com esses resultados os benefícios produtivos do aumento da lâmina de água para a palma forrageira são mais evidentes, supostamente em regiões com níveis pluviométricos bastante reduzidos em comparação com regiões nas quais os valores de precipitação superam $740 \mathrm{~mm}$ (Flores-Hernández et al., 2004).

Em relação aos índices morfofisiológicos, também não foram constatados efeitos significativos das lâminas (Figura 1).

A TAL (Figura 1E) é o índice que exprime a correlação entre a área foliar e a produção de matéria seca da planta, considerada como a fotossíntese líquida e que apresentou relação inversa ao IAC da cultura em cujas lâminas com maior IAC ocorreram os menores valores de TAL; este resultado é devido ao autossombreamento da cultura, uma vez que os maiores números de cladódios da planta pertencem às ordens inferiores. Tal constatação também é confirmada em estudos para outras culturas, em que o autossombreamento das folhas promove redução nos valores da TAL (Valmorbida et al., 2007), além do fato de cladódios jovens poderem contribuir menos para fotossíntese, quando comparados a cladódios mais velhos.

Condições que favorecem o aumento do IAC, como adubação, irrigação, densidade de plantas, espaçamento e, entre outros, também contribuem para menores valores de TAL, logo que a menor área foliar estará exposta à radiação solar (Flores-Hernández et al., 2004; Costa et al., 2012). Flores-Hernández et al. (2004) verificaram valores médios de TAL na ordem de 44,5 $\mathrm{g} \mathrm{m}^{-2} \mathrm{mês}^{-1}$, para quatro clones de palma forrageira, valor este inferior ao obtido neste experimento.

A TCA apresentou valor médio de $68,01 \mathrm{~g} \mathrm{~m}^{-2} \mathrm{mês}^{-1}$ (Figura $1 F)$ e, diferentemente da TAL, os maiores valores foram verificados nas lâminas que apresentaram maior IAC. 

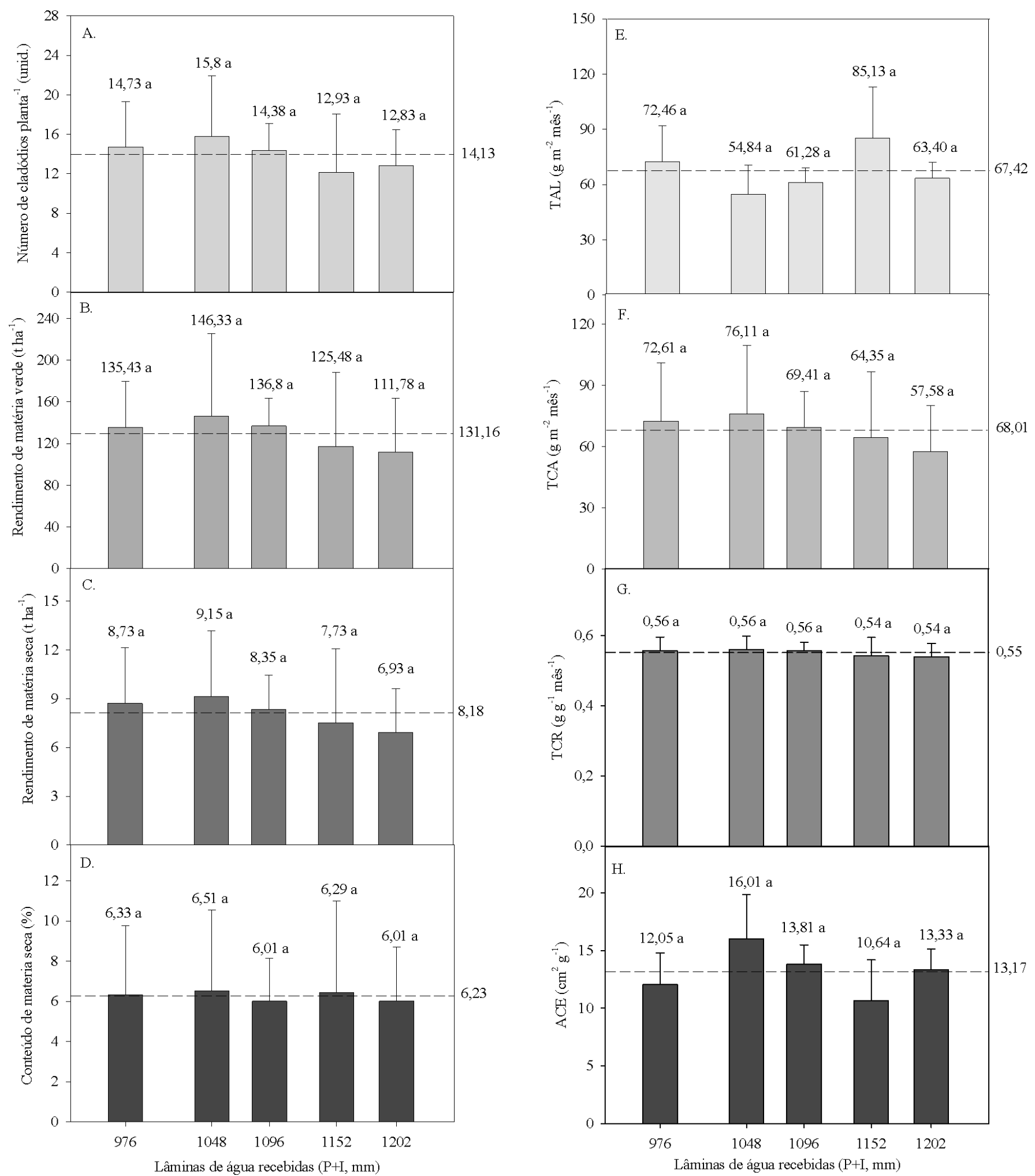

Médias seguidas pela mesma letra não diferem significativamente (Teste de Tukey). Barras verticais representam a média \pm erro padrão, $p>0,05$

Figura 1. Parâmetros produtivos $(\mathrm{A})$ número de cladódios médios, (B) rendimento de matéria fresca, $(\mathrm{C})$ rendimento de matéria seca, (D) conteúdo de matéria seca) e índices morfofisiológicos (E) TAL - Taxa de assimilação liquida; (F) TCA - Taxa de crescimento absoluto; (G) TCR - Taxa de crescimento relativo; (H) ACE - Área de cladódio específica, do clone de palma forrageira, cv. Orelha de Elefante Mexicana/IPA 2000-16, aos 380 DAC, sob diferentes lâminas de irrigação no Semiárido brasileiro

Almeida (2011) verificou, avaliando as cultivares gigante (Opuntia sp.) e doce (Nopalea sp.) nas condições climáticas de Rafael Jambeiro - BA, submetidas a diferentes adubações (orgânica, química e orgânica + química), incrementos médios de TCA de até $97 \%$ para o terceiro sistema de adubação em relação à testemunha, com todos os tratamentos apresentando taxas lineares ao longo do ciclo (900 DAP).

A TCR mostra a velocidade no acúmulo de biomassa em relação a uma quantidade de biomassa pré-existente. Almeida (2011) encontrou, para a palma forrageira, valores de TCR 
oscilando entre $0,032 \mathrm{~g} \mathrm{~g}^{-1} \mathrm{~d}^{-1}$ (adubação orgânica) até $0,035 \mathrm{~g}$ $\mathrm{g}^{-1} \mathrm{~d}^{-1}$ (orgânico-química) aos 180 DAP.

Estudos sobre o crescimento da palma forrageira utilizando índices morfofisiológicos, são escassos na literatura, sendo mais facilmente encontrados para outras culturas. Por exemplo, como citado por Souza et al. (2007) para a cultura do abacaxi (CAM), com a utilização de irrigação suplementar, que exibiu valores de TCR e TAL inicialmente elevados, os quais decresceram ao passar dos dias, devido à translocação dos compostos foliares para outros órgãos da planta.

A ACE, assim como a TAL, também exprime uma relação entre a produção de matéria seca e o IAC; no entanto, este índice quantifica a distribuição de matéria seca na superfície fotossintetizante e, na grande maioria dos casos, relaciona-se inversamente com a espessura dos cladódios; em média, seu valor foi $13,17 \mathrm{~cm}^{2} \mathrm{~g}^{-1}$ (Figura $1 \mathrm{H}$ ); assim, quanto maior for a superfície específica maior também será o investindo em área foliar, sem custo adicional de biomassa para a formação de maior área foliar. Plantas de ciclo perene tendem a ter baixa TCR e AFE, com alta capacidade de acumulação de reservas; maior superfície específica favorece uma interceptação mais adequada da radiação fotossinteticamente ativa.

\section{Conclusões}

1. As lâminas de água aplicadas não promoveram alterações significativas nas características morfofisiológicas nem na produtividade da palma forrageira, porém os resultados mostraram tendência de que lâminas na faixa entre 1048 a $1090 \mathrm{~mm}$, em base anual, promovem melhores respostas da cultura.

2. Os valores médios do número de cladódios, biomassa verde e seca durante 380 dias, em condições irrigadas, foram superiores aos observados na literatura em cultivos de sequeiro, inclusive com ciclos superiores (> 380 dias).

3. Os índices de resposta hídrica da cultura, assim como o índice de cobertura do solo e índice de volume de produção, tenderam a um decréscimo com o aumento da lâmina aplicada; os cladódios de primeira ordem são os mais distribuídos na planta $(48,50 \%)$ e aqueles que mais contribuem para o IAC total da planta $(48,65 \%)$.

4. É possível utilizar os índices de resposta hídrica e índices morfológicos propostos neste estudo, bem como índices morfofisiológicos, a fim de se verificar o desempenho da palma forrageira, de maneira relativamente simples e exploratória.

\section{Literatura Citada}

Allen, R. G.; Pereira, L. S.; Raes, D.; Smuth, M. Crop evapotranpiration: Guidelines for computing crop water requirements, Rome: FAO, 1998. 301p. Irrigation and Drainage Paper 56.

Almeida, J. A palma forrageira na região Semiárida do estado da Bahia: diagnóstico, crescimento e produtividade. Cruz das Almas: UFRB, 2011. 97p. Tese Doutorado

Araújo Primo, J. T.; Silva, T. G. F.; Siqueira e Silva, S. M.; Moura, M. S. B. L. S. B. Calibração de sondas capacitivas, funções físico-hídricas e variação do armazenamento de água em um argissolo cultivado com palma forrageira. Revista Ceres, v.62, p.20-29, 2015. http:// dx.doi.org/10.1590/0034-737X201562010003
Bajgain, R.; Kawasaki, Y.; Akamatsu, Y.; Tanaka, Y.; Kawamura, H.; Keisuke Katsura; Shiraiwa, T. Biomass production and yield of soybean grown under converted paddy fields with excess water during the early growth stage. Field Crops Research, v.180, p.221-227, 2015. http://dx.doi.org/10.1016/j. fcr.2015.06.010

Bispo, S. V.; Ferreira, M. A.; Veras, A. S. C.; Batista, A. M. V.; Pessoa, R. A. S.; Bleuel, M. P. Palma forrageira em substituição ao feno de capim-elefante. Efeito sobre consumo, digestibilidade e característica de fermentação ruminal em ovinos. Revista Brasileira de Zootecnia, v.36, p.1902-1909, 2007. http://dx.doi. org/10.1590/S1516-35982007000800026

Costa, F. S.; Suassuna, J. F.; Melo, A. S.; Brito, M. E. B.; Mesquita, E. F. Crescimento, produtividade e eficiência no uso da água em bananeira irrigada no semiárido paraibano. Revista Caatinga, v.25, p.26-33, 2012.

Consoli, S.; inglese, G.; inglese, P. Determination of evapotranspiration and annual biomass productivity of a cactus pear (Opuntia ficusindica L. (Mill.) orchard in a Semi-arid Environment. Journal of Irrigation and Drainage Engineering, v.139, p.680-690, 2013. http://dx.doi.org/10.1061/(ASCE)IR.1943-4774.0000589

Dubeux Júnior, J. C. B.; Santos, M. V. F.; Lira, M. A.; Santos, D. C.; Farias, I.; LIMA, L. E.; Ferreira, R. L. C. Productivity of Opuntia fícus-indica (L) Miller under different $\mathrm{N}$ and $\mathrm{P}$ fertilization and plant population in north- east Brasil. Journal of Arid Enviroments, v.67, p.357-372, 2006. http://dx.doi.org/10.1016/j. jaridenv.2006.02.015

Flores-Hernández, A.; Castillo, I. O.; Amador, B. M.; Hernández, J. L. G.; Troyo-Dieguez, E. Yield and physiological traits of prickly pear cactus 'nopal' (Opuntia spp.) cultivars under drip irrigation. Agricultural Water Management, v.70, p.97-107, 2004. http:// dx.doi.org/10.1016/j.agwat.2004.06.002

Leite, M. L. M. V. Avaliação de clones de palma forrageira submetidos a adubações e sistematização de informações em propriedades do Semiárido paraibano. Areia: UFPB, 2009. 186p. Tese Doutorado

Nascimento, J. P.; Souto, J. S.; Santos, E. S.; Damasceno, M. M.; Ramos, J. P. F.; Sales, A. T.; Leite, M. L. M. V. Caracterização morfométrica de Opuntia ficus-indica sob diferentes arranjos populacionais e fertilização fosfatada. Revista Tecnologia \& Ciência Agropecuária, v.5, p.21-26, 2011.

Oliveira, F. T.; Souto, J. S.; Silva, R. P.; Andrade Filho, F. C.; Pereira Júnior, E.B. Palma forrageira: Adaptação e importância para os ecossistemas áridos e semiáridos. Revista Verde de Agroecologia e Desenvolvimento Sustentável, v.5, p.27-37, 2010.

Oliveira Júnior, S.; Barreiro Neto, M.; Ramos, J. P. F.; Leite, M. L. M. V.; Brito, E. A.; Nascimento, J. P. Crescimento vegetativo da palma forrageira (Opuntia fícus-indica) em função do espaçamento no Semiárido paraibano. Revista Tecnologia \& Ciência Agropecuária, v.3, p.7-12, 2009.

Pinheiro, K. M.; Silva, T. G. F.; Carvalho, H. F. S.; Santos, J. E. O.; Morais, J. E. F.; Zolnier, S.; Santos, D. C. Correlações do índice de área do cladódio com características morfogênicas e produtivas da palma forrageira. Revista Pesquisa Agropecuária Brasileira, v.49, p.939-947, 2014. http://dx.doi.org/10.1590/S0100204X2014001200004 
Ramos, J. P. F.; Leite, M. L. M. V.; Oliveira Júnior, S.; Nascimento, J. P.; Santos, E. M. Crescimento vegetativo de Opuntia ficus-indica em diferentes espaçamentos de plantio. Revista Caatinga, v.24, p.41-48, 2011.

Silva, N. G. M.; Santos, M. V. F.; Dubeux Júnior, J. C. B.; Mello, A. C. L.; Silva, M. C. Relação de características morfológicas e produtivas de clones de palma-forrageira. Revista Brasileira de Zootecnia, v.39, p.2389-2397, 2010. http://dx.doi.org/10.1590/ S1516-35982010001100011

Silva, T. G. F.; Araújo Primo, J. T.; Morais, J. E. F.; Diniz, W. J. S.; Souza, C. A. A.; Silva, M. C. Crescimento e produtividade de clones de palma forrageira no semiárido e relações com variáveis meteorológicas. Revista Caatinga, v.28, p.10-18, 2015.

Silva, T. G. F.; Araújo Primo, J. T.; Silva, S. M. S.; Moura, M. S. B.; Santos, D. C.; Silva, M. C; Araújo, J. E. M. Indicadores de eficiência do uso da água e de nutrientes de clones de palma forrageira em condições de sequeiro no Semiárido brasileiro. Revista Bragantia, v.73, p.184-191, 2014a. http://dx.doi.org/10.1590/brag.2014.017
Silva, T. G. F.; Miranda, K. R.; Santos, D. C.; Queiroz, M. G.; Silva, M. C.; Cruz Neto, J. F.; Araújo, J. E. M. Área do cladódio de clones de palma forrageira: modelagem, análise e aplicabilidade. Agrária, v.9, p.633-641, 2014b. http://dx.doi.org/10.5039/agraria. v9i4a 4553

Silva, T. G. F.; Zolnier, S.; Grossi, J. A. S.; Barbosa, J. G.; Moura, C. R. W.; Muniz, M. A. Crescimento do girassol ornamental cultivado em ambiente protegido sob diferentes níveis de condutividade elétrica de fertirrigação. Revista Ceres, v.56, p.602-610, 2009.

Souza, C. B.; Silva, B. B.; Azevedo, P. V. Crescimento e rendimento do abacaxizeiro nas condições climáticas dos Tabuleiros Costeiros do Estado da Paraíba. Revista Brasileira de Engenharia Agrícola e Ambiental, v.11, p.134-141, 2007. http://dx.doi.org/10.1590/ S1415-43662007000200002

Valmorbida, J.; Boaro, C. S. F.; Scavroni, J.; David, E. F. S. Crescimento de Mentha piperita L., cultivada em solução nutritiva com diferentes doses de potássio. Revista Brasileira de Plantas Medicinais, v.9, p.27-31, 2007. 